\title{
Efeito do estiramento à frio no aço utilizado na fabricação de rodas avali- ado por propriedades mecânicas
}

\author{
1Alencar M.A. * 1 Barbosa, L.P., 1Mucsi C.S., 1Rossi, A., 1Rossi J.L. \\ 1 Instituto de Pesquisas Energéticas e Nucleares - IPEN \\ * e-mail: milton.alencar@fatec.sp.gov.br
}

\begin{abstract}
Resumo
Este estudo teve como objetivo a investigação e avaliação das propriedades mecânicas, antes e depois, dos processos de soldagem e do estiramento (metal spinning) do aço utilizado na fabricação de rodas para caminhões e ônibus. Comercialmente, a roda é constituída de dois componentes, o aro e o disco. $\mathrm{O}$ estiramento na fabricação de rodas é utilizado para aumentar a largura do componente aro, e na conformação do componente disco, que devem atender perfis determinados em projeto, de modo a resistir aos testes de fadiga por ciclagem e de momentos de flexão e torção, alternados. A presente proposta estudou os efeitos do processo de estiramento, pois com o melhor entendimento destes efeitos, poder-se-á maximizar a otimização da massa da roda, um importante objetivo a ser alcançado para o setor de fabricação de rodas de aço. Os métodos propostos para a identificação dos efeitos do estiramento no aço empregado para a fabricação de rodas foram ensaios de tração, análise metalográfica, análise do comportamento das deformações do material durante os ensaios de tração, utilizando a técnica de correlação de imagens digitais (DIC), somados a mapas de dureza, executados no material antes e após o processo de estiramento. As variações dos percentuais de redução de espessuras no processo de estiramento foram correlacionadas com as variações de resistência a tração, para verificação da relação da variação de espessura com a variação dos valores de resistência a tração, evidenciando um aumento na tensão de ruptura a tração a cada aumento de percentual de redução de espessura do material no estiramento, chegando a um aumento de $50 \%$ na resistência a tração, numa redução de $55 \%$ na espessura da matéria prima, com a consequente perda na deformação.
\end{abstract}

Palavras-Chave: estiramento, metalográfico, resistência à tração, mapas de dureza, correlação de imagens digitais (DIC).

\begin{abstract}
This research aims investigate and analyze the mechanical properties, before and after the welding and metal spinning process, in the steel used to fabricate bus and truck wheels. The metal spinning in the manufacturing of the wheels is used to widen the width of the rim, and in working the shape of the disc, that must be accordance to design project, in order to be approved in the bending and torsion fatigue testing. The present approach of this research is to better understand of the metal spinning effects, to maximize the optimization of the wheel mass, one of the biggest aims to be achieved by the wheel industries. The methods proposed to identify the spinning effects in the wheel's steel were tensile test, the material's deformation behavior using digital image correlation (DIC), metallographic analyzes, added to hardness maps, executed in the material's before and after of the metal spinning process. The percentual variations of reduction were correlated with tensile tests results. The results show an increase of $50 \%$ in the tensile strength for the raw material reduced $55 \%$ in thickness, and consequent loss in the maximum strain.
\end{abstract}

Keywords: metal spinning, metallographic, tensile test, hardness maps, digital images correlation (DIC).

\section{Introdução}

A indústria automobilística, procurando a diminuição de custos e aumento de desempenho de seus produtos, sempre está interessada na redução de peso nos automóveis. Para isto, um item que pode contribuir de 
maneira bem eficiente é a roda. Uma alternativa é a matéria prima, no caso liga de alumínio, ou a redução de espessuras quando a matéria prima é o aço. Visto que os diâmetros e larguras das rodas estão vinculados ao projeto do veículo. No caso de caminhões, as rodas de alumínio apresentam um custo muito elevado para o consumidor, comparado ao custo de rodas de aço. $O$ que justifica investimentos nos processos de fabricação de rodas de aço, com o objetivo de se reduzir seu peso. Uma opção é a redução das espessuras dos componentes, com a utilização do processo de estiramento (metal spinning process), que consiste na conformação a frio, por roletes laminadores, que pressionam o material em alta rotação, sobre um mandril, que possui o formato interno do componente. Este processo proporciona melhorias de desempenho do produto com redução estratégica de espessura. Essa redução por estiramento proporciona à roda uma geometria de melhor desempenho nos testes de resistência, e causa um efeito benéfico na curva tensão deformação do aço empregado, no que diz respeito ao aumento da resistência a tração, ou seja, mesmo com um aço de baixo carbono, consegue-se aprovar rodas em testes bem rígidos de resistência à fadiga por ciclagem.

\section{Metodologia}

O método proposto para o estudo dos efeitos do processo de estiramento no aço utilizado na fabricação de rodas, foi ensaios de tração, por serem normalmente adotados como simulação física para a análise das deformações características do processo de estiramento, de acordo com Suttner e Merklein, análise das deformações do material durante os ensaios através da correlação de imagens digitais (DIC), utilizando o software GOM Correlate, mapas de dureza, somados a análise metalográfica óptica. Para tanto, foram usinados corpos de prova com dimensões reduzidas de acordo com a norma ASTM E8 [2], de modo a minimizar o uso de materiais e permitir ensaios mecânicos em máquinas de laboratório, e deste material também foram retiradas amostras para a metalografia óptica. Os corpos de prova foram usinados a partir do material de discos e aros estirados com variações de espessura. 0 objetivo destes experimentos foi identificar quais as mudanças entre o material não processado, e o material depois de processado. O material utilizado neste trabalho foi ao aço ABNT 1015, conforme NBR NM $87: 2000$, laminado a quente, cujas composições químicas estão listadas na Tabela 1, pertencente ao material do componente aro e Tabela 2 pertencente ao material do disco. Os componentes dos quais foram retiradas as amostras para a confecção dos corpos de prova, foram executados dentro das instalações da empresa do grupo Maxion, rodas de aço, em Guarulhos e Cruzeiro, durante o processo contínuo de fabricação. Depois de preparados os corpos de prova, estes foram ordenados de acordo com suas espessuras finais após o processo de estiramento, e organizados em grupos conforme mostrado na Tabela 3, material do disco e Tabela 4, material do aro, respectivamente. E então foram executados três ensaios de tração de cada grupo, na máquina universal de ensaios INSTRON no laboratório de ensaios mecânicos, nas instalações do IPEN, Instituto de Pesquisas Energéticas e Nucleares, a temperatura ambiente, com a velocidade do travessão de $1 \mathrm{~mm} / \mathrm{min}$.

\begin{tabular}{|c|c|c|c|c|c|c|}
\hline C & Mn & $\mathbf{P}$ & $\mathbf{S}$ & Si & $\mathrm{Cr}$ & Al \\
\hline 0,164 & 0,359 & 0,0180 & 0,009 & 0,008 & 0,018 & 0,023 \\
\hline \multicolumn{7}{|c|}{ Fonte: Certificado do material Companhia Siderúrgica Nacional (CSN) } \\
\hline \multicolumn{7}{|c|}{ Tabela 2: Composição química (\% massa) material do disco } \\
\hline C & Mn & $\mathbf{P}$ & $\mathbf{S}$ & Si & $\mathrm{Cr}$ & Al \\
\hline 0,15 & 0,486 & 0,013 & 0,0044 & 0,014 & 0,016 & 0,035 \\
\hline
\end{tabular}

\begin{tabular}{c|c|c|c}
\multicolumn{4}{c}{ Tabela 3: Corpos de prova com espessura inicial de 12,7 mm (Disco) } \\
\hline $\begin{array}{c}\text { Espessura } \\
\text { Estirada }\end{array}$ & $\begin{array}{c}\% \text { de } \\
\text { Redução }\end{array}$ & Identificação & Quantidade \\
\hline 7 & $45 \%$ & MD05 & 3 \\
\hline 6,5 & $49 \%$ & MD02 & 3 \\
\hline 6,3 & $50 \%$ & MD04 & 3 \\
\hline 5,9 & $54 \%$ & MD03 & 3 \\
\hline 5,7 & $55 \%$ & MD01 & 3 \\
\hline 12,7 & $0 \%$ & MDB127 & 3
\end{tabular}

\begin{tabular}{c|c|c|c}
\multicolumn{4}{c}{ Tabela 4: Corpos de prova com espessura inicial de 12 mm (Aro) } \\
\hline $\begin{array}{c}\text { Espessura } \\
\text { Estirada }\end{array}$ & $\begin{array}{c}\% \text { de } \\
\text { Redução }\end{array}$ & Identificação & Quantidade \\
\hline 7,7 & $36 \%$ & MA09 & 3 \\
\hline 8 & $33 \%$ & MA05 & 3 \\
\hline 8,3 & $31 \%$ & MA 02 & 3 \\
\hline 8,5 & $29 \%$ & MA 06 & 3 \\
\hline 9,5 & $21 \%$ & MA 11 & 3 \\
\hline 9 & $25 \%$ & MA 10 & 3 \\
\hline 12 & $0 \%$ & MAB12 & 3
\end{tabular}

Para a utilização da técnica de correlação de imagens digitais (DIC), a superfície dos corpos de prova foi pintada de forma matizada, como mostrada na Figura 1, para a criação de diversos pontos com distribuição estocástica, de fundamental importância para a correta utilização do programa de computador necessário para as análises. Todos os ensaios de tração foram filmados com uma câmera Cannon com resolução de imagem de $1920 \times 1080$ pixels, para garantir a melhor qualidade possível do vídeo, para o processamento do software GOM Correlate, utilizado como ferramenta de análise 
de deformações durante o ensaio de tração. De modo a melhor compreender os deslocamentos resultantes das deformações no ensaio, na região da estricção do material.

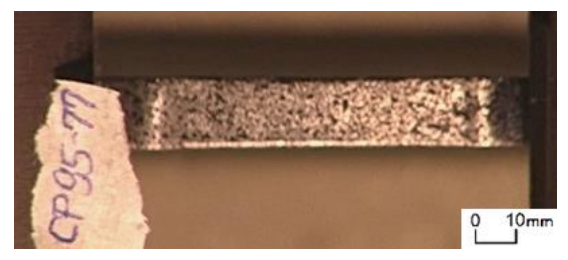

Figura 1 - Corpo de prova com pintura matizada.

Depois de realizados os ensaios de tração, foram executados todos ao gráficos tensão-deformação, para uma análise dos resultados. Neste universo de resultados, foram feitos os gráficos das médias de cada grupo, e foram estes gráficos das médias, os utilizados para as análises. Inclusive foram feitas análises cruzadas entre os materiais do aro e do disco, com a finalidade de observar alguma tendência entre componente (aro/disco) ou processos de estiramento, linear [3] para o aro, e de cisalhamento para o disco [3]. Para a análise metalográfica do material, foram retiradas amostras do material bruto, das diversas espessuras estiradas, do material na região soldada, antes e depois da operação de estiramento, de modo a se conseguir criar um paralelo entre o material na situação bruta, depois de manufaturado e depois de soldado a topo e manufaturado. $O$ procedimento para o preparo das amostras para a metalografia foi planejado de modo a evitar alterações nas microestruturas, conforme normas ASTM E3-01 [4] e ASTM E-407 [5], para se conseguir a análise das durezas e estrutura do material. O material para as amostras do disco foi retirado no sentido radial do produto, já o material para as amostras do aro foi retirado no sentido axial do um aro. Do material do aro foram cortadas fatias no sentido transversal a região soldada, paralelas e perpendiculares ao sentido de estiramento, e transversal e paralela ao sentido de estiramento do material do disco. De modo a analisar o comportamento do material de acordo com o sentido do estiramento.

\section{Discussão dos resultados}

Nos ensaios de tração ficou evidenciado que houve um aumento médio de $50 \%$ na tensão de ruptura a tração máxima suportada pelas amostras, com a consequente queda de aproximadamente $70 \%$ no alongamento. 0 que foi evidenciado nos diversos gráficos comparativos que foram executados com os dados colhidos nos ensaios de tração, como exemplificado no Gráfico 1 e Gráfico 2. Confirmando o exposto por Chiaverini [6], e demonstrando que o aumento da resistência à tração é função do percentual de redução em relação a espessura inicial do material. A diferença no comportamento dos valores das tensões entre o material do aro e do disco pode ser resultado da presença da solda a topo no material do aro, já que o material utilizado para ambos é o mesmo aço baixo carbono, o processo estiramento também é o mesmo, porém o aro é resultado de estiramento linear [3] e o disco de estiramento de cisalhamento [3].

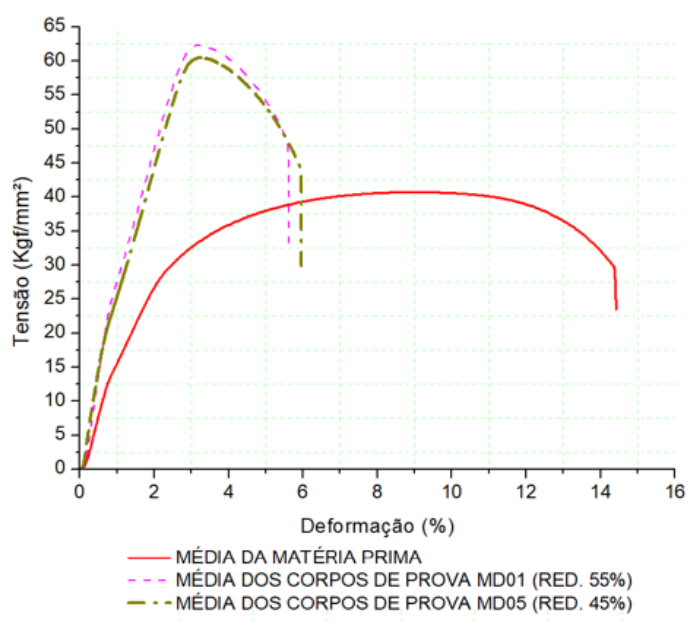

Gráfico 1 - Comparativo Tensão x Deformação material do Disco.

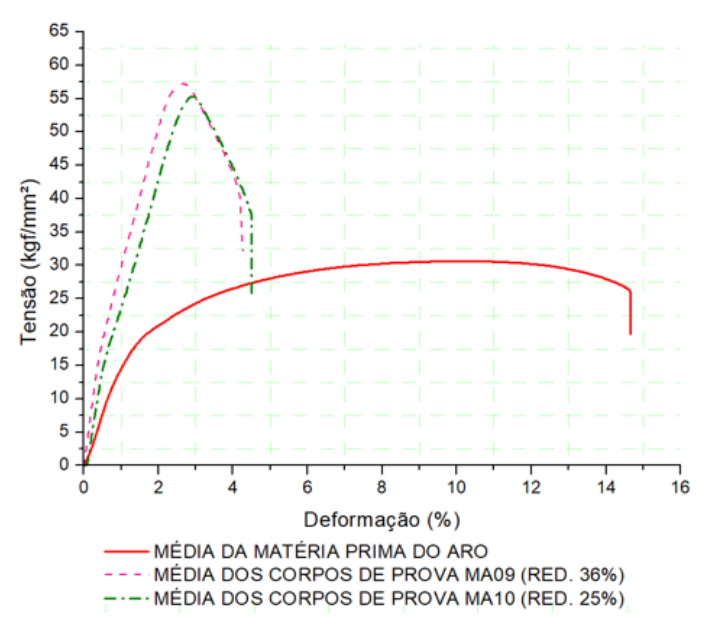

Gráfico 2 - Comparativo Tensão x Deformação material do Aro.

Outra forma de demonstrar isto está no Gráfico 3, que compara o comportamento do material do disco (MD05) e do aro (MA09) na máxima proporção de redução, em relação a espessura da matéria prima de cada um. A metalografia do material em bruto, mostrada na figura 2, confirmou o aspecto normal de um aço baixo carbono, compatível com a composição de um aço hipoeutetóide [6]. Já na metalografia do material após processado por estiramento, mostrou os grãos mais refinados na face externa do estirado (a), enquanto na face em contato com o mandril (b), os grãos se apresentam maiores, figura 3. A razão provável para esta diferença na granulometria é a diferença na velocidade de resfriamento causada pelo sistema de refrigeração, que atinge somente a face externa na peça, durante o processo de conformação. Fato evidenciado pela figura 4, 
que mostra a metalografia das mesmas regiões da solda, na peça antes da conformação. Em micrografias feitas com as amostras retiradas no sentido longitudinal (a) e transversal (b) do material do disco, mostradas na figura 5, o formato do grão é alongado, resultado do processo de conformação.

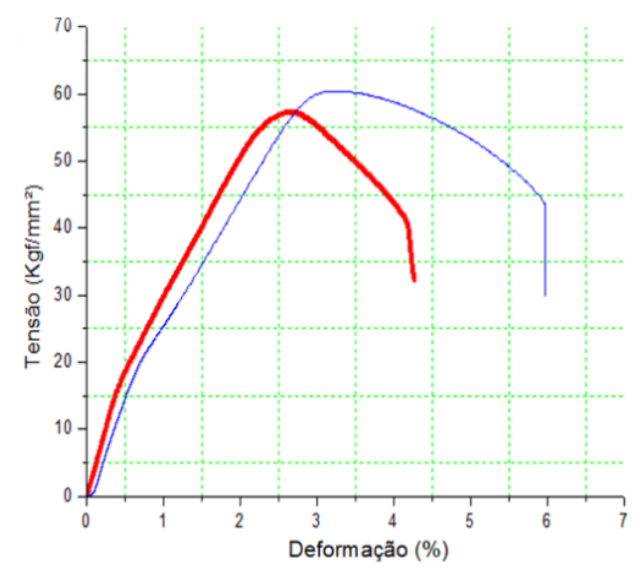

- MÉDIA DOS CORPOS DE PROVA MA09 (RED. 36\%)

Gráfico 3 -Comparativo Tensão x Deformação material do aro e do disco.

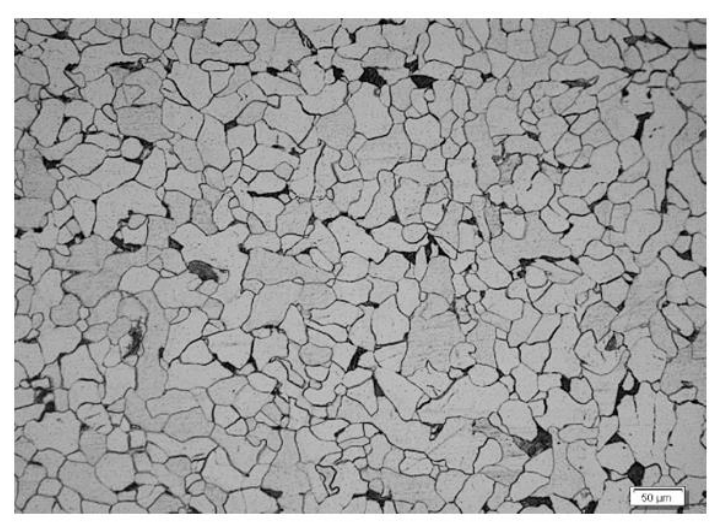

Figura 2 - Micrografia do material em bruto (200x). Ataque: Nital 3\%.

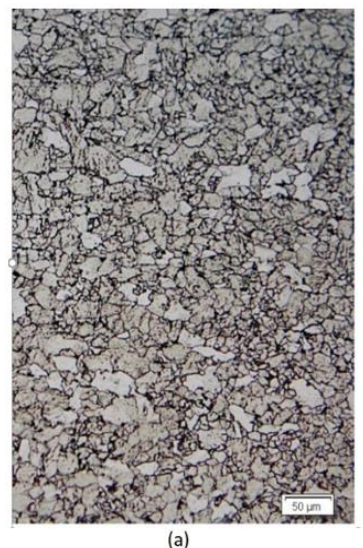

(a)

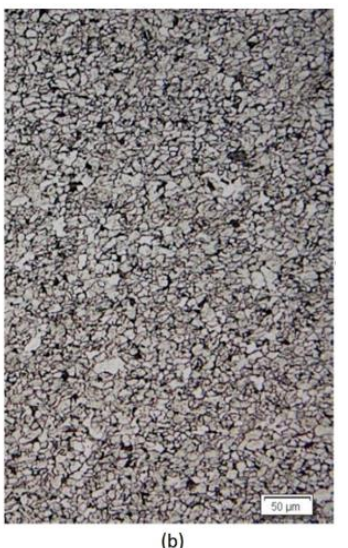

(b)
Figura 3 - Micrografia do material após operação de estiramento (200x).

Ataque: Nital 3\% Face interna (a). face externa (b)

Os mapas de dureza foram executados com os dados colhidos em um microdurômetro Buehler 5114, de acordo com as especificações da norma ASTM 384-99 [7] e ASTM E3-92 [8], utilizando a carga de $3 \mathrm{~kg}$, por 15 segundos, em grupos de pontos igualmente espaçados, respeitando o distanciamento maior que 2,5 o valor da diagonal da impressão entre impressões e da borda da amostra, no sentido da largura e espessura das amostras do material em bruto, e no material após o processo de estiramento.

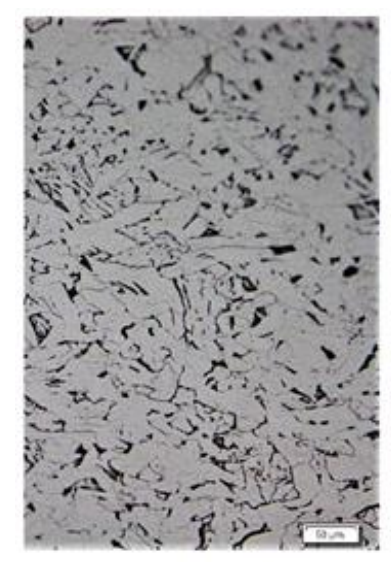

(a)

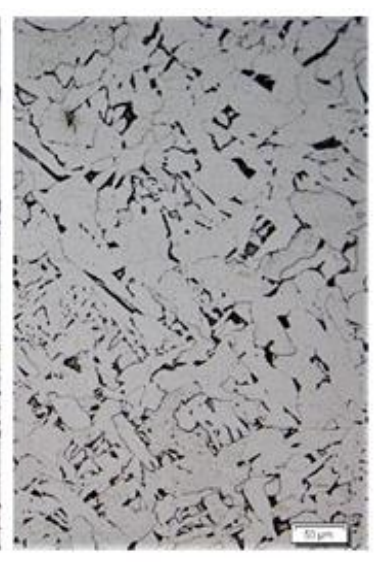

(b)
Figura 4 - Micrografia do material antes da operação de estiramento (200x). Ataque: Nital $3 \%$. Face externa (a), face interna (b)

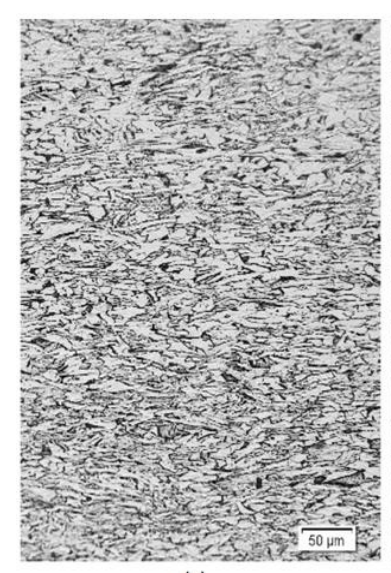

(a)

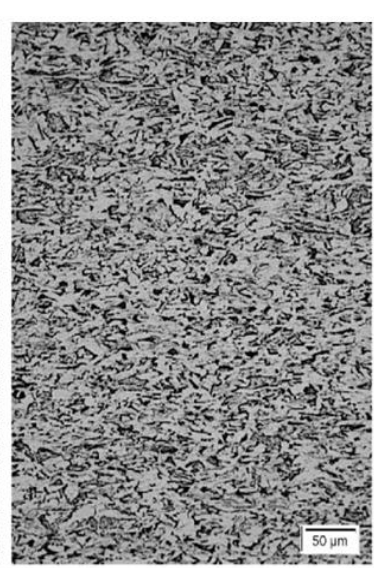

(b)
Figura 5 - Micrografia do material do disco(200x). Ataque: Nital 3\%. Sentido longitudinal (a), sentido transversal (b).

$\mathrm{Na}$ análise do deslocamento do material durante o ensaio de tração, feita com o auxílio do programa de computador GOM Correlate, foi possível acompanhar na linha do tempo do ensaio o momento do início do deslocamento, e quadro a quadro acompanhar as deformações resultantes entre pontos determinados sobre a superfície do corpo de prova. Devido a isto, foi possível analisar o deslocamento de pares de pontos durante o ensaio, o que demonstrou um comportamento diferente entre a face interna e externa do material estirado, quando analisado na espessura, como mostrado na figura 6. Esta análise sugere que a diferença do comportamento do material do aro em relação ao material do disco, é a diferença do tamanho do grão da face interna em relação do tamanho do grão da face 
externa, tendo como base o modelo de Hall-Petch, que demonstra a relação no ganho de resistência e aumento na tensão de escoamento do material, com a redução do tamanho do grão, conforme Whang [9].

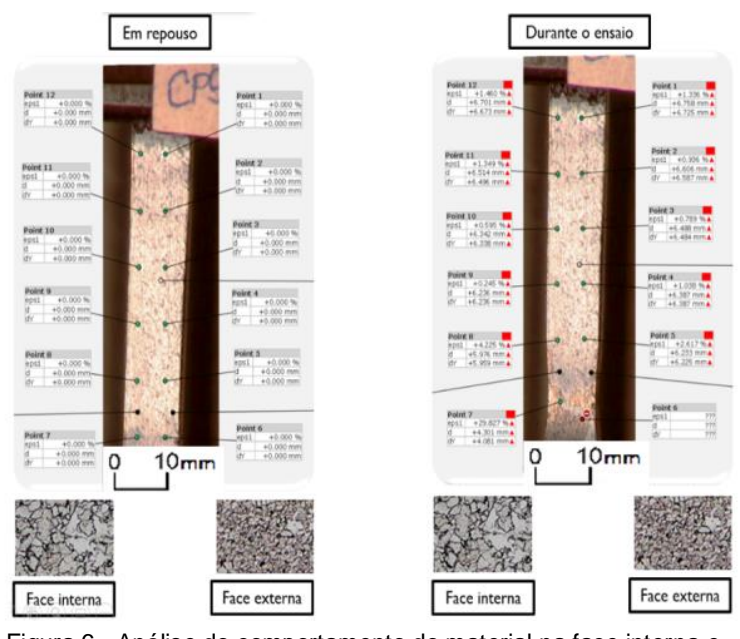

Figura 6 - Análise do comportamento do material na face interna e externa, durante o ensaio de tração.

O gráfico 4 mostra o comportamento de dureza com encruamento de ambas as faces do material em bruto, resultado de um laminador com os cilindros atuando simultaneamente nas duas faces, durante a manufatura, e ocasionando o aumento da dureza quando as medições se aproximam das faces da chapa, fato mostrado pela curva das médias.

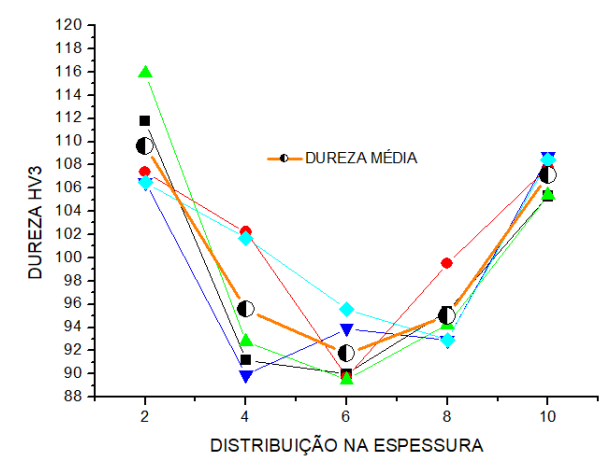

Gráfico 4 - Comportamento da dureza Vickers no sentido da espessura de uma amostra em bruto, antes do processo de estiramento.

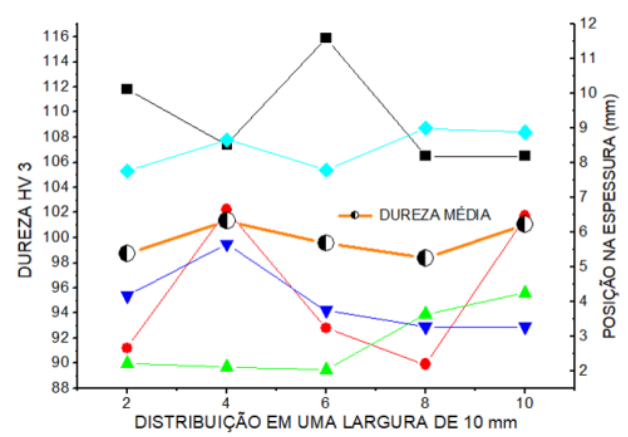

Gráfico 5 - Comportamento da dureza Vickers no sentido da largura do material em bruto, antes da operação de estiramento

E no gráfico 5, conseguimos observar o comportamento da dureza no sentido da largura, um pouco mais estável quando analisado como distribuído em linha de dureza na espessura.

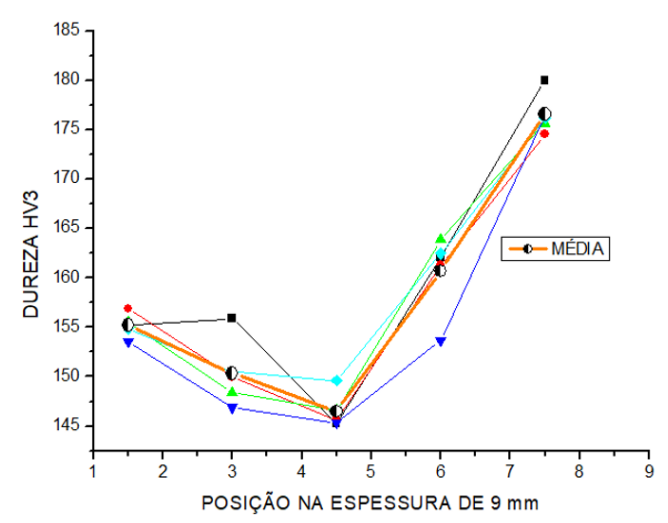

Gráfico 6 -Comportamento da dureza Vickers no sentido da espessura do material, após a operação de estiramento.

No gráfico 6 pode-se observar a distribuição da dureza no sentido da espessura do material que passou pelo processo de estiramento, a partir da face interna, que esteve em contato com o mandril durante o processo de estiramento.

\section{Conclusão}

Os resultados alcançados neste trabalho indicaram a possibilidade de que o método estiramento (metal spinning), utilizado para se executar o componente roda de aço para caminhão e ônibus, ou a presença da solda a topo no material, influenciará em seu desempenho, no que tange ao comportamento da resistência mecânica do material, se a característica analisada for a deformação. E constatam que o comportamento do aço utilizado para a fabricação de rodas de ônibus e caminhão, utilizando o processo de estiramento, adquirem as propriedades mecânicas necessárias para a garantia do atendimento dos requisitos de segurança, impostos pelas condições de utilização destes produtos nos veículos para os quais forem destinados, devido ao ganho de resistência a tração pelo encruamento, com valores próximos a $62 \mathrm{kgf} / \mathrm{mm}^{2}$, intrínsecos no processo de estiramento utilizado. Fatores que também colaboram para dificultar a propagação de trincas superficiais, melhorando o desempenho dos componentes nas ciclagens nos ensaios de fadiga. O que possibilita a otimização do projeto do componente, pela redução da espessura utilizada, com a redução de custos e economia de recursos ambientais no manuseio e produção da matéria prima utilizada.

\section{Agradecimentos}

Os autores agradecem ao IPEN Instituto de Pesquisas Energéticas e Nucleares, ao grupo Maxion Wheels, e a Fatec Itaquera pelo apoio 


\section{Encontro Científico de Física Aplicada}

\section{Referências}

[1] S. Suttner e M. Merklein, "A new approach for the determination of the linear elastic modulus from unxial tensile tensile tests of sheet metals," Journal of Materials Processing Technology, pp. 64-72, 2017.

[2] ASTM, E 8M Test Methods for Tension Testing of Metallic Materials, vol. 03.01, Pennsylvania, 2001.

[3] C. Wong, T. Dean e J. Lin, "A review of spinning, shear forming and flow forming processes," International Journal of Machine Tools \& Manufacture, vol. 43, pp. 1419 - 1435, 2003.

[4] ASTM, E3-01 Standard Guide for Preparation of Metallographic Specimens, vol. 3.01, Pennsylvania, 2004.

[5] ASTM, E 407 Test Methods for Microetching Metals and Alloys, vol. 3.11, 2004.
[6] V. Chiaverini, Aços e Ferros Fundidos, 6a ed., A. B. d. Metais, Ed., São Paulo: ABM, 1990.

[7] ASTM, E 384-99 Standard Test Method for Microindentation Hardness of Materials, vol. 3.01, A. International, Ed., West Conshohocken, Pensylvania, 1999.

[8] ASTM, E3-92 Standard Test Method for Vickers Hardness of Metallic Materials, vol. 3.01, Pennsylvania, 2004.

[9] S. h. Whang, "Nanostructured metals and alloys," Woodhead Publishing, 2011, pp. 299-328. 